\title{
DATA DETERMINANTS OF THE ACTIVITY OF SMES AUTOMOBILE DEALERS
}

\author{
David SALVETAT \\ Professor \\ ESSCA School of management \\ Phone: 06.58.23.11.62 \\ david.salvetat@essca.fr \\ Jean-Sébastien LACAM \\ Associate Professor \\ ESSCA School of management \\ Clermont Recherche Management (CleRMa) \\ Phone: 06.72.08.85.24 \\ jean-sebastien.lacam@essca.fr \\ 1 rue Lakanal - BP 40348 \\ 49003 Angers cedex 01 - France
}

\begin{abstract}
Many SMEs still seem reluctant to accept the management of large datasets, which still appear to be too complex for them. However, our study reveals that the majority of small French car dealers are developing Big data and Smart data policies to improve the quality of their offers, the dynamism of their sales and their access to new opportunities. However, not every policy has the same effects on the development of their business. Whereas Big data improves all the components of SME development in a global, short-term and operational way, Smart data presents itself as a more targeted, prospective and strategic approach.
\end{abstract}

\section{Keywords}

Big data, smart data, development, automobile, SME.

\section{Standard JEL codes}

M100, M150. 


\section{Introduction}

For several years, the exploitation of data has become increasingly popular with both large and small firms, due to its potential benefits in terms of knowledge, decision making and, ultimately, performance (financial, commercial, organizational, etc.) (Cetindamara, Phaalb \& Probertb, 2016). With a turnover of $\$ 203$ billion forecast by 2020 (IDC, 2016), the economic promise offered by big data now affects all sectors of the new and old economies. Like many manufacturing industries, the automobile industry is now destabilized by the unprecedented volume, velocity and variety of data available to it (Laney, 2001). For example, the volume of business generated by the production and sale of connected vehicles is expected to almost triple by 2020 (PWC, 2016). In addition to embedded electronic boxes (known as dongles), the use of mobile phones, social networks, websites, etc. increases the amount of data that can inform the automobile industry about the purchasing behavior of connected motorists. This new knowledge offers the ability to bring about the gradual transformation of the commercial relationship through the use of data relating to the vehicle (defects, wear and tear, etc.), the driver (uses, needs, etc.) and his/her commercial environment (after-sales service, customer experience, etc.).

A CCM Benchmark Institut (2015) survey revealed that 56\% of French Internet users search online before buying a new car. Now, customers only visit a dealership once, on average, before buying (five years earlier, the average customer would have visited five showrooms). While $31 \%$ of the first commercial contacts are still initiated during a physical meeting for the sale of new vehicles, more than half of these contacts now come from the Internet for sales of used vehicles, technical maintenance and after-sales care. The transmission and processing in real time of data on the technical condition of a vehicle and its use (breakdown, obsolescence of equipment, types of driving, etc.) also opens up a whole new field of business opportunities around repair and vehicle maintenance. To be better served, $90 \%$ of 2.0 consumers choose to authorize access to their personal data. This therefore presents a particularly important economic stake for small concessions that encounter difficulties in developing (financial limitations, high investment costs, and insufficient critical size) in an increasingly concentrated distribution market. With the ability to manage large and diversified datasets efficiently, small automobile distributors could improve their strengths in each of the following areas: the quality of service and customer satisfaction with their three areas of trade (the sale of new and used vehicles, parts sales and after-sales). Professionals still, however, need to know how to use data; during the year of our investigation, more than one in three French customers had not been 
contacted by their car dealership. Finally, even when professionals collect and store data, the data are often incomplete, perhaps even false, and, therefore, ineffective. Despite its economic promise, the exploitation of data presents small organizations with technical and organizational challenges that require the mobilization of numerous financial, human and material resources (Alles, 2015 ; McAfee \& Brynjolfsson, 2012). Many small and medium-sized enterprises (SMEs) are, therefore, still reluctant to implement this technology, which they consider too complex (Soroka, Liu, Han, \& Haleem, 2017). Despite these obstacles, however, some work in the literature does mention the deployment of data exploitation programs by small firms and their expected impact on the firms' distribution activities (Manyika et al., 2011). Therefore, to shed light on the analysis of digital practices developed so far by SMEs and their possible economic gains (George, Haas, \& Pentland, 2014; Sen, Ozturk, \& Vayvay, 2016), we wanted to address the following research question: Does the exploitation of data positively impact the development of small firms in the automobile distribution industry?

To answer this question, a quantitative study was carried out among 112 SMEs in French automobile distribution (small car dealerships). Guided by our desire on this issue to bring together these firms' decision makers and management science, our results make three main contributions. First, small French car dealerships have become aware of the economic importance of managing data to develop their activities. Our study reveals that the vast majority of the SMEs that participated actively use their data to support the development of their business. More precisely, and this is the second result of the survey, these organizations stand out through the deployment of three data policies, whose volume, variety and speed of exploitation of data diverge. These policies correspond to No data, Big data and Smart data programmes. The identification of a typology of data policies thus underlines the state of progress of data use among small automobile distributors. Third, the study reveals that Big data and Smart data policies improve development. Whereas Big data has a general, short-term and operational influence on the three areas of development (i.e. the quality of their offers, the dynamism of their sales and their access to new opportunities), Smart data represents a more targeted, anticipatory and strategic approach by facilitating the changes to be carried out, mainly in improving the quality of their offers and the dynamism of their sales. Thus, each data policy must be carefully selected and then deployed according to the fields and practices that the small car dealership wishes to develop. 


\section{Theoretical foundations}

\subsection{The 'datafication' of automobile distribution}

New technologies have caused a profound change in the formulation of strategies in the majority of companies (Liébana-Cabanillasa \& Alonso-Dos-Santos, 2016).Today, the large multi-dimensional datasets generated by firms' various stakeholders (customers, suppliers, competitors, etc.) are growing under the influence of the Internet of Things, geographic information systems (GIS), connected objects, social media, etc. According to Wagner, Bachor \& Ngai (2014), the processing of these data represents a real competitive advantage for a firm through the potential organizational knowledge that can result from it. Whereas a firm might once have used a few megabytes of data in several days, it can now perform the same operation in a continuous flow in eminently larger volumes. Real-time access to information in its interand intra-organizational environment makes a firm more agile than its competitors by virtue of its knowledge and anticipation of its customers' needs, the optimal management of its stock or the fair pricing of its offers (Boyer, 2016). As a result, data have increased in recent years in various industries, such as the automobile industry. For example, both the manufacturers' distribution networks and independent aftermarket firms are endeavoring to make commercial use of the data produced continuously by the dongle that equips a growing fleet of vehicles that are now connected. The redefinition of various services or the emergence of new devices and services associated with this new connectivity (the sale of new or second-hand vehicles, parts sales and after-sales services) represents tremendous business opportunities for firms capable of controlling data flows. A sign that data are now a strategic issue is that new players are also appearing in automobile distribution. This is the case with the AutoVisual platform, which classifies used vehicle advertisements by informing individuals about price positioning based on market value, and by developing services for automobile professionals to help them source supplies, maximize their margins and understand how the used-car market evolves. In recent years, big data have become popular because of the explanatory and predictive benefits that can be derived from exploiting a large volume of both structured (from customer relationship management $[\mathrm{CRM}]$ or other traditional databases) and unstructured (from sensors, Web applications, Global Positioning System [GPS], etc.) data that are fed to the organization without interruption and in real time. 'Big data' is, therefore, not only concerned with the generation and processing of 'massive' data; it also involves an extraordinary diversity of data (internal/external, private/public, collective/individual and ambient) that are delivered at high velocity and frequency. Thus, Gartner (Laney, 2001) defined the phenomenon in 2001 through 
the founding of the $3 \mathrm{Vs}$ (volume, velocity and variety) model, which has been enriched to date by components relating to the veracity, value and variability of data (Chen, Preston, \& Swink, 2015).

While big data promise to help managers become more familiar with their environment and make better decisions (Cetindamara, Phaalb \& Probertb, 2016), the challenge of exploiting the data in the service of their managerial objective is particularly complex (Brown-Liburd, Issa, \& Lombardi, 2015). However, it is making a success of this process of creating knowledge from masses of raw and heterogeneous data that ensures the profitability of such a digital policy (George et al., 2014). Beyond the traditional 3Vs model, the challenge lies in an organization's ability to generate data that are 'intelligent' (Goes, 2014). This is where big data become smart data. It is no longer necessary to process a high volume and variety of data to create value. In response to a predefined usage objective, data are identified and then detected more effectively due to the delimitation of a precise and thus reduced research theme. The firm is thus developing its approach around the selection, evaluation and intelligent use of a smaller volume of data (Davenport \& Patil, 2012; Huang \& Huang, 2015). In this sense, some experts no longer value big data and smart data, but small data, with the idea of democratizing data analysis in terms of the resources available to devote to it, enabling the smallest firms (such as SMEs) to exploit data (intelligently). These small data, whose volume and format facilitate their processing, are generally present in all organizations because they concern basic information, such as customer contact details, expenses, comments on the Internet, etc. However, regardless of their nature, data remain inherently 'stupid' and it requires capability to use them wisely. Consequently, the benefits generated by their management require a transformation of the firm's information technology, cognitive and organizational capacities (Brown-Liburd et al., 2015). However, the necessary investments in technological, human, financial, organizational and other resources may prove to be significant, depending on the firm's size, structure area of activity (Alles, 2015; Golia, 2013).

\subsection{Influence of data on the development of automobile industry SMEs}

All the major industries of the old economy (including the automobile industry) draw on data as development sources. The evaluation to date ensures the attractiveness and strategic importance of data for large and small firms alike. For SMEs, which account for $99.8 \%$ of European businesses, economic growth depends to a large extent on their development, which in turn depends on their ability to innovate through the adoption of new technologies (Oxford 
Economics Survey, 2013). Big data is a key technology that stimulates innovation, economic growth, development by increasing the responsiveness, flexibility, productivity and anticipation of SMEs through the new ability to analyze and predict market movements (Sen et al., 2016). Furthermore, an absence of large datasets should not exempt SMEs from such a program. Regardless of the volume available to them, it has become essential for SMEs to make maximum use of data in order to gain a market share, develop their offer and improve their organizational processes. Finally, the existence of outsourced services, such as cloud computing, is now helping SMEs to meet the technical, financial and human challenges of data utilization (Soroka et al., 2017). As a result, McKinsey Global has identified potential gains from a policy of exploiting data for SMEs distribution activity (Manyika et al., 2011). Knowledge generated by this program could improve SME development by optimizing, for example, the design and placement of firms' offers and hence their commercial performance. Despite obstacles arising from the significant amount of resources required to mobilize and drive a digital policy, many SMEs are currently exploiting 'massive' or 'intelligent' data in the hope of improving the quality of their offer(s), developing their sales and stimulating the expansion of their market(s) by accessing new business and organizational opportunities (Soroka et al., 2017). In view of the above, we wonder, therefore, about the real influence of data on these three components of development with respect to SMEs in French automobile distribution.

Chandler (2015) argues that the collection and processing of data in a firm's intra- and interorganizational environments should make it possible to optimize the quality of its offer. For example, the process of improving the quality of a product or service can be enriched by analyzing data from the practices, behaviors or comments of customers (Warren, Moffitt, \& Byrnes, 2015). Product creation can also emerge from data handling that enables the effective management of an ecosystem of stakeholders or the comprehensive and integrated planning of all the functions in a value chain. For example, McAfee and Brynjolfsson (2012) note the use of 'massive' data among automobile manufacturers to understand the reasons for higher defect and return rates for some models. Some first automakers involved their sales network in largescale data management. For several years, they used data from their distributors as the basis of a predictive analysis solution to better detect faults in their vehicles before the production of future series. Automakers request that all dealers of their brand have the capacity to receive, process and share (without interruption or fragmentation) commercial, technical, environmental, behavioural data, etc. from their customers and their connected cars. This 
requirement comes at a time when the brand's small dealers, mainly because of their insufficient size and financial limitations, are increasingly subordinate to the manufacturer. However, automakers imposing their IT infrastructure on their dealers (like the majority of manufacturers), it is clear that, in practice, IT tools are under-exploited by the sales teams, which, reinforced by the frequent use of independent infrastructures, does not favour the connection of all these data, the sources of which are highly diverse. Many automakers have concentrated their networks in France, with the aim of strengthening national concessions at the expense of other firms of more modest size. Consequently, their data strategy has to contend with the reluctance of certain small distributors to make their data fully accessible to the manufacturer. For example, groups CRM that will tomorrow entirely guide the relationship between the seller and the customer (consequently, who will return the sale between the manufacturer and the dealer?). Beyond the relational difficulties that these data policies engender, the burden placed on small dealers is technical and organizational because these digital developments are also likely to have an impact on the management of the work within the showrooms and workshops.

In addition to developing the necessary IT tools, automakers require that dealers integrate the "data management" function into their work processes and increase the skills of their sales teams in order to bring about new business opportunities, such as real-time remote vehicle diagnostics. Coupled with predictive maintenance, utilizing data from on-board and connected boxes, real-time remote diagnostics transforms automotive distribution activities in order to improve the quality of the services provided in dealerships or garages. Several networks, such as those of Mercedes-Benz France and the PSA Group, now provide technicians with a system for collecting all the data necessary for carrying out an intervention adapted to users' expectations (available parts, technical sheets, tutorials, etc.). Despite all the constraints that are placed on small organizations, the effective use of data makes it possible to access new development perspectives and better exploit limited resources. Therefore, the use of data, for example from customer or employee feedback, should improve the quality of the offers from small car distributors by helping them better understand and anticipate the requirements of their market. Thus, we formulate the following hypothesis (see Figure 1):

Hypothesis 1. (H1) The more actively an automobile SME manages its data, the more the quality of its offers increases. 
The technologies gradually being more widely used are transforming the customer experience at the point of sale and allowing consumers to understand new uses. As a result, as part of a digital policy, SMEs most often retain and exploit customer and sales data (Soroka et al., 2017). From online sales to connected applications and dongles, and via their presence on social networks, automobile dealers are beginning to develop a whole digital system to benefit from a global vision of a customer base. Thus, dealers benefit from a platform that allows for the prequalification of prospects (on the basis of analyses of online behavior, feedback, etc.) and can detail their relationship with sales representatives with profiles corresponding to their needs (rapid sales, qualitative support, etc.). As a result of the analysis and cross-checking of all these data, firms should be able to offer consumers personalized commercial offers (complementary and/or promotional offers, adapted prices, personalized loans, etc.) and thus improve their sales (Chandler, 2015). We therefore formulate the following hypothesis (see Figure 1):

Hypothesis 2. (H2) The more actively an automobile SME manages its data, the more its sales increase.

According to Chen et al. (2015), big data bring to a firm a new vision of its business model but can also help it obtain new business opportunities. Blanchard and O'Sullivan (2015) state that data allow firms to evolve their offers in line with changing trends and personalize them according to the various customer profiles identified. According to Soroka et al. (2017), the analysis of customer and sales data offers SMEs the opportunity to expand their offers and markets. Sen et al. (2016) argue in turn that data utilization improves, on the one hand, the decision support systems developed by SMEs and, on the other, guides them in the simulation of various business scenarios. In addition, big data can influence a firm's organizational processes by transforming its methods and operational tools or by helping it better manage its human resources (Chen et al., 2015; Grimm \& Konig Ingentis, 2015). Through the data-mining and behavioral analysis platform that serves its dealerships, some automakers are mobilizing their sales force in a different way (such as by taking appointments after the pre-qualification of customers using data to improve the quality and performance of its customer support). Data offer, therefore, unprecedented opportunities for firms that want to improve their products and services, expand their markets and optimize their operations (Chen et al., 2017). A final hypothesis is formulated as follows (see Figure 1):

Hypothesis 3. (H3) The more actively an automobile SME manages its data, the more its business and internal organization opportunities increase. 
Figure 1. Theoretical model

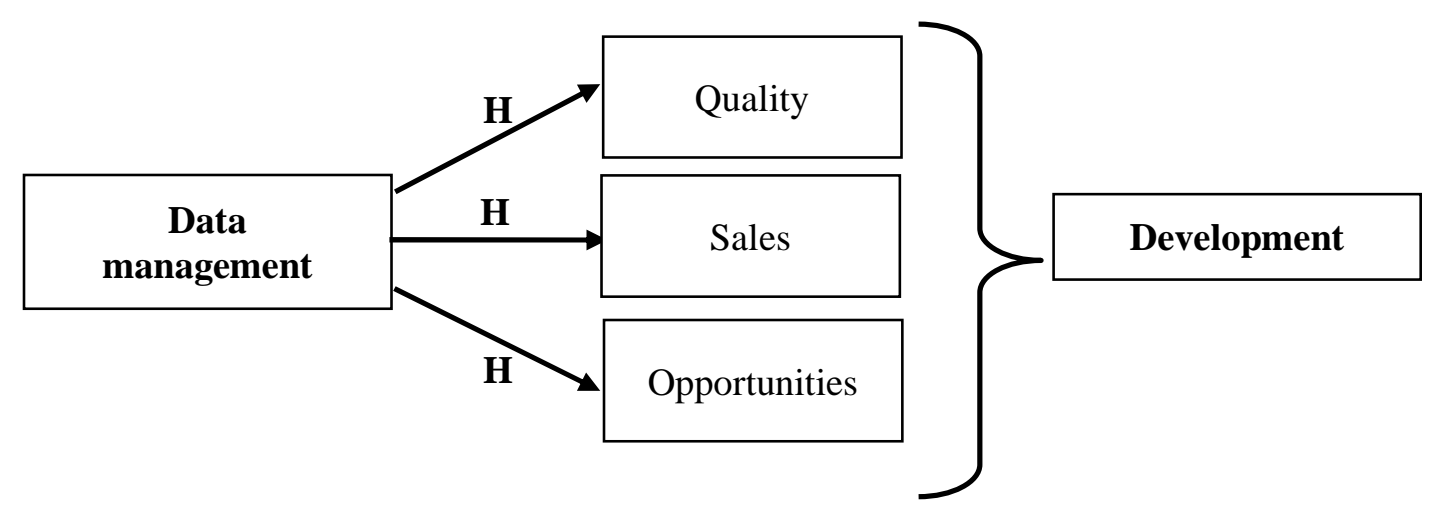

\section{Research design}

\subsection{Automobile industry and sampling}

Our empirical study deals with the management of data by French automobile dealers. In the French automobile industry, 31,000 firms are divided between those selling new and used vehicles and those offering maintenance and sales of spare parts (ANFA, 2016). These firms are manufacturers who have their own branches, a secondary network of manufacturers' partners including dealerships, agents and garages, and various suppliers outside these networks (agents, supermarkets, car accessory outlets, etc.) sourcing from manufacturers' foreign subsidiaries, dealers, etc. Drawn from a sample based on an equal probability of being chosen, 1,600 dealers were approached via our online research questionnaire (see Appendix).

Following data purification (incomplete questionnaires, those returned after the deadline, etc.), 112 firms were selected (see Table 1). According to the criteria of the European Commission (2003/361/EC), 33\% are small organizations (10 but fewer than 50 employees and a turnover between 2 million and 10 million euros) and 67\% are medium-sized firms (from 50 to 250 employees and a turnover of between 10 million and 50 million euros). 


\section{Table 1. Survey details}

Number of questionnaires received during the survey period

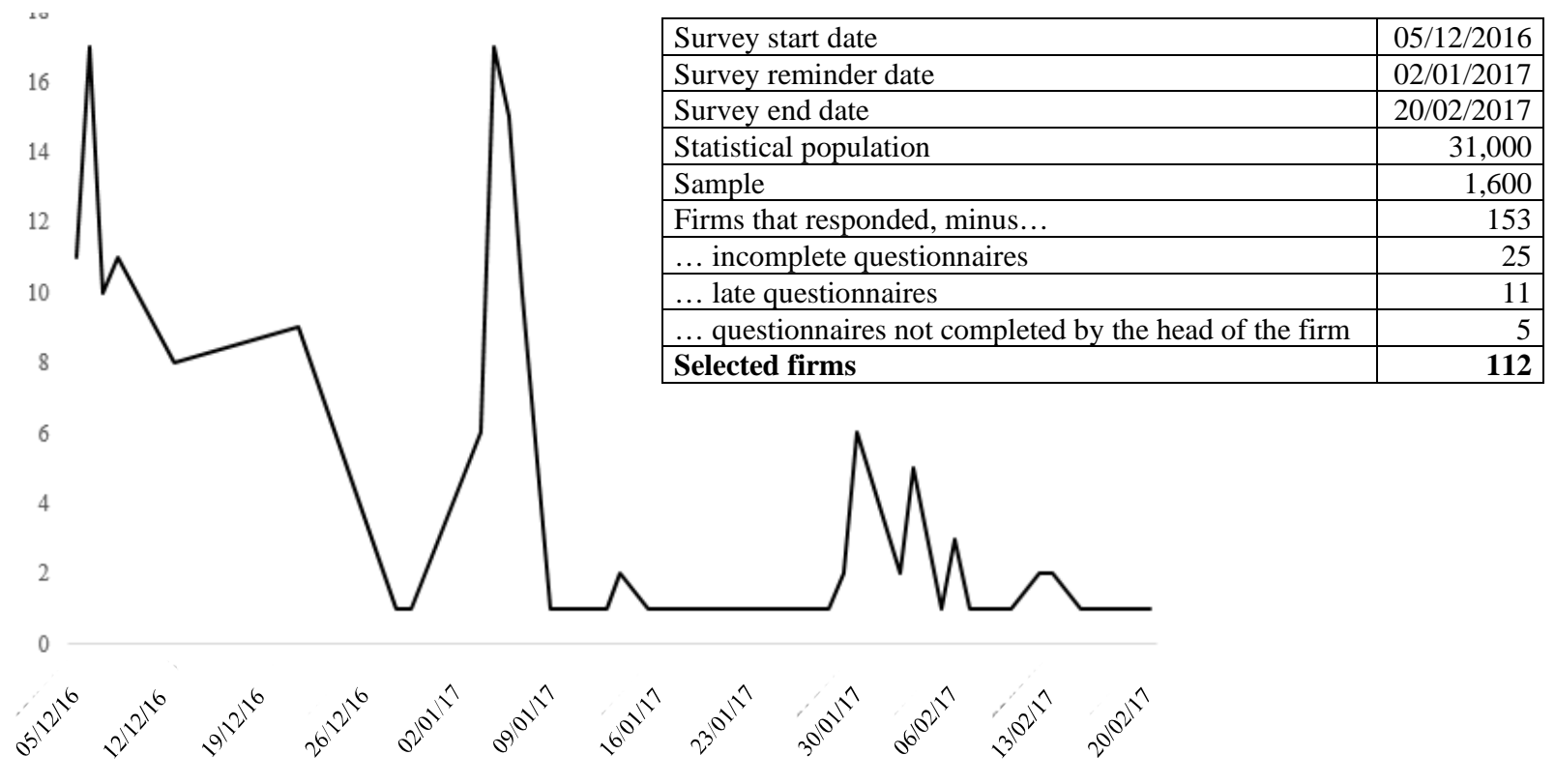

Distribution of the selected 112 firms by category of firm and data policy

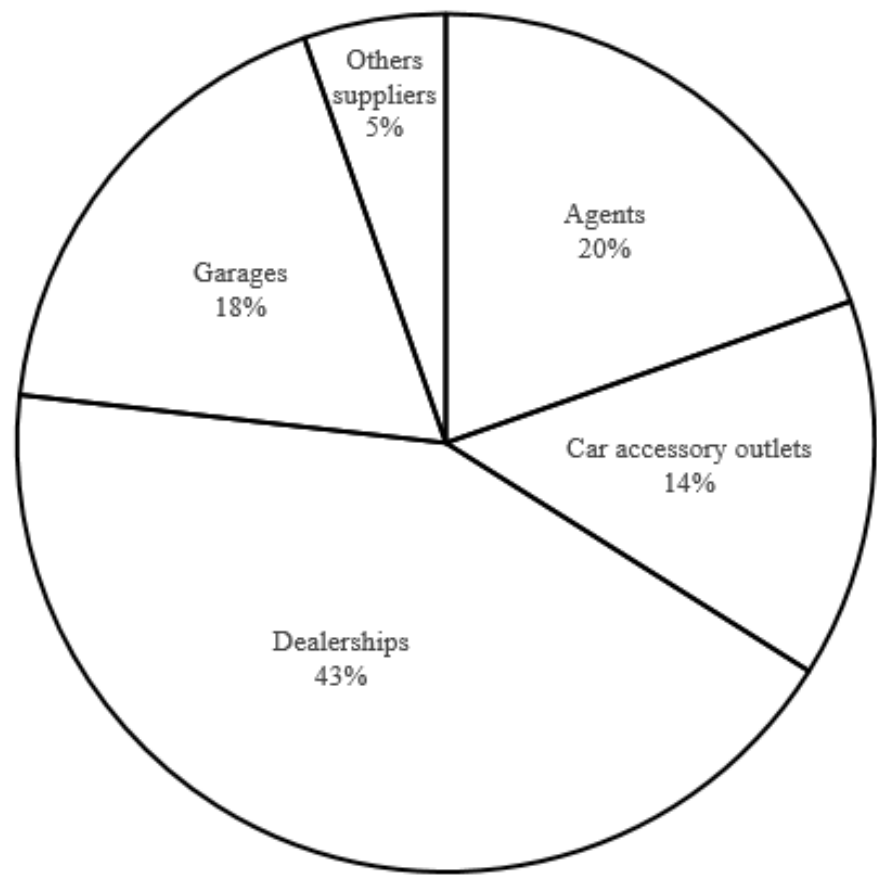

\begin{tabular}{|l|c|c|c|}
\cline { 2 - 4 } \multicolumn{1}{c|}{} & No data & Big data & Smart data \\
\hline Agents & $33 \%$ & $17 \%$ & $20 \%$ \\
\hline Car accessory outlets & $17 \%$ & $16 \%$ & $8 \%$ \\
\hline Dealerships & $25 \%$ & $43 \%$ & $52 \%$ \\
\hline Garages & $25 \%$ & $17 \%$ & $16 \%$ \\
\hline Other suppliers & $0 \%$ & $7 \%$ & $4 \%$ \\
\hline
\end{tabular}




\subsection{Variables}

The dependent macro variable (Development) and seven independent macro variables and variables were used to measure the data utilization policies and their consequences for the economic expansion of French automobile dealers. The CPA and CFA validated the reliability, quality and discriminative validity of these scales of measurement (see Table 2).

\subsubsection{Dependent macro variable}

The Development macro variable comprises three variables and measures, in relation to a firm's data utilization, the quality of its offers (improvement of quality, reduction of defect rates, etc.), sales (stimulation of demand, increase in sales, etc.) and the new business and organizational opportunities that arise (opening up new markets, progression of offers, new ways of working, etc.). The items are mainly drawn from articles by Brulhart and Moncef (2010), Kleinschmidt, De Brentani and Salomo (2007) and Samani and Moghaddam (2014).

\subsubsection{Independent macro variables and variables}

Drawn from the 3Vs model (Laney, 2001), the three macro variables Volume, Velocity and Variety define the type of data utilization that an automobile dealer deploys.

The Volume macro variable assesses the amount of data collected and produced by a company. It consists of three variables: low volume (annual quantity of data assessed as limited by the respondent), standard volume and high volume. The Velocity macro variable evaluates the velocity of data retrieval (continuous/discontinuous) and associated decision making (realtime/delayed time). It is composed of two variables: reduced data velocity (discontinuous and delayed data flow) and high data velocity (continuous and real-time data flow). The Variety macro variable assesses the diversity of data (texts, figures, images, etc.) and their timeliness (old/recent data).

The two Source macro variables measure the means of data collection by a firm and its collaborator(s). These are made up of four variables: the institutional (professional bodies, public institutions, etc.) and horizontal (competitors and allies) sources of the firm; and the personal (friends, family, etc.) and professional (associations, trade unions, etc.) sources of the individuals working in the company. The items are drawn from articles by Boyer (2016) and George et al. (2014). 
The Customer relationship macro variable assesses the impact of data on the links and exchanges maintained between a dealer and its customers. It is made up of four variables: relational quality (response to needs, trust, etc.), delivery times (timeliness, duration of deadlines, etc.), follow-up (claims management, assistance, etc.) and customer satisfaction (measurement tools, reduction of complaints, etc.). These items are mainly drawn from articles by Brulhart and Moncef (2010) and Samani and Moghaddam (2014).

Finally, the Data mining macro variable evaluates the organizational use of the data collected by an automobile dealer. It is made up of three variables: flexibility (modification to offers, distribution, etc. caused by data utilization, etc.), cost control (improvement of forecasts, reduction of costs, etc.) and human resources (employee involvement, motivation, participation, etc.). The items are mainly drawn from an article by Xiang (2013).

\section{Control variables}

The Diane database provided four control variables to complete the study: Firm size (effective), Sales revenue, Total assets and the Seniority of the firm. 


\begin{tabular}{|c|c|c|c|c|c|c|c|c|c|c|c|c|c|c|c|}
\hline \multicolumn{5}{|c|}{ Table 2. Tests of variables (PCA and CFA) } & \multicolumn{5}{|c|}{ AI } & \multicolumn{5}{|c|}{ RI } & \multirow{2}{*}{$\frac{\text { IP }}{\chi^{2} / d d l}$} \\
\hline \multirow{2}{*}{ Macro variables } & \multirow{2}{*}{ Variables } & \multirow{2}{*}{ MW } & \multirow{2}{*}{ IR } & \multirow{2}{*}{$\alpha$} & $\chi^{2}$ & GFI & $A G F I$ & RMR & RMSEA & NFI & $R F I$ & CFI & IFI & $T L I$ & \\
\hline & & & & & $+\downarrow$ & \multicolumn{2}{|c|}{$\geq 0.9$} & $\approx 0$ & $<0.09$ & \multicolumn{5}{|c|}{$\geq 0.9$} & $<5$ \\
\hline \multirow{3}{*}{ Development } & Quality & PCA & 0.749 & 0.787 & & & & & & & & & & & \\
\hline & Sales & CFA & 0.713 & 0.863 & 0.474 & 0.998 & 0.99 & 0.007 & 0.001 & 0.998 & 0.995 & 1 & 1.006 & 1.018 & 0.237 \\
\hline & Opportunities & CFA & 0.641 & 0.801 & 1.9 & 0.992 & 0.96 & 0.017 & 0.001 & 0.991 & 0.972 & 1 & 1.001 & 1.002 & 0.95 \\
\hline \multirow{2}{*}{ Velocity } & Reduced & CFA & 0.333 & 0.75 & \multirow{2}{*}{9.1} & \multirow{2}{*}{0.974} & \multirow{2}{*}{9.31} & \multirow{2}{*}{0.068} & \multirow{2}{*}{0.036} & \multirow{2}{*}{0.963} & \multirow{2}{*}{0.931} & \multirow{2}{*}{0.995} & \multirow{2}{*}{0.995} & \multirow{2}{*}{0.991} & \multirow{2}{*}{1.137} \\
\hline & High & CFA & 0.313 & 0.827 & & & & & & & & & & & \\
\hline Variety & & PCA & 0.658 & 0.73 & & & & & & & & & & & \\
\hline \multirow{3}{*}{ Volume } & Low & CFA & 0.253 & 0.845 & \multirow{3}{*}{4.6} & \multirow{3}{*}{0.987} & \multirow{3}{*}{0.953} & \multirow{3}{*}{0.042} & \multirow{3}{*}{0.081} & & & & & & \\
\hline & Standard & CFA & 0.279 & 0.961 & & & & & & 0.989 & 0.972 & 0.99 & 0.989 & 0.958 & 0.766 \\
\hline & High & CFA & 0.241 & 0.823 & & & & & & & & & & & \\
\hline Firm sources & Institutional & CFA & 0.401 & 0.687 & 1197 & 0.995 & 0.947 & 0.029 & 0.042 & 0.986 & 0.919 & 0.998 & 0.998 & 0.986 & 1197 \\
\hline & Horizontal & CFA & 0.359 & 0.603 & & & & & & & & & & & \\
\hline & Personal & CFA & 0.405 & 0.741 & & & & & & & & & & & \\
\hline Collaborator sources & Professional & CFA & 0.273 & 0.5 & 1 & 0.997 & 0.987 & 0.018 & 0.001 & 0.991 & 0.978 & 1 & 1.029 & 1.076 & 0.2 \\
\hline & Relational quality & PCA & 0.715 & 0.866 & & & & & & & & & & & \\
\hline & Delivery times & CFA & 0.641 & 0.809 & 2.4 & 0.989 & 0.943 & 0.026 & 0.045 & 0.986 & 0.959 & 0.997 & 0.997 & 0.992 & 1.2 \\
\hline Customer relationship & Follow-up & CFA & 0.696 & 0.854 & 0.1 & 1 & 0.999 & 0.003 & 0.001 & 1 & 0.999 & 1 & 1.009 & 1.026 & 0.05 \\
\hline & Customer satisfaction & PCA & 0.878 & 0.89 & & & & & & & & & & & \\
\hline & Flexibility & PCA & 0.586 & 0.822 & & & & & & & & & & & \\
\hline Data mining & Cost control & CFA & 0.673 & 0.833 & 2.8 & 0.988 & 0.94 & 0.018 & 0.061 & 0.988 & 0.964 & 0.996 & 0.996 & 0.989 & 1.4 \\
\hline & Human resources & PCA & 0.729 & 0.907 & & & & & & & & & & & \\
\hline
\end{tabular}

Notes: $P C A=$ principal component analysis; $C F A=$ confirmatory factor analysis; $A I=$ absolute indices; $R I=$ related indices; $I P=$ indices of parsimony; $M W=$ methods withheld; $I R=$ information restitued; $\alpha=$ Cronbach's alpha; $\chi^{2}=C h i^{2} ; G F I=$ goodness-of-fit index; $A G F I=$ adjusted goodness-of-fit index; $R M R=$ root mean residual; $R M S E A=$ root mean square error of approximation; $N F I=$ normed fit index; $R F I=$ relative fit index; $C F I=$ comparative fit index; $I F I=$ incremental fit index; $T L I=$ Tucker-Lewis index; $\chi^{2} / d d l=$ Chi ${ }^{2}$ by the degree of freedom. 


\subsection{Data processing}

Principal component analysis (PCA) and confirmatory factor analysis (CFA) allowed the variables to be constructed and validated according to several indicators (Cronbach's alpha, absolute indices, etc.), whose acceptability thresholds and results are set out in the Appendices (see Table 2). Groups of firms with distinctive profiles were then formed using k-means clustering. Euclidean distance and CPA or CFA factor scores assessed the proximity of groups to minimize the existence of relationships between the variables. Based on the factor scores, the analysis of variance (ANOVA) confirmed our typology.

The explanatory powers of the factorial axes (F-test) and their meanings were also calculated. Discriminant analysis validated the results of this classification and the barycenters of the groups were measured. Based on the 3Vs model (Laney, 2001), the analysis of the three macro variables regarding the type of data utilization (volume, velocity and variety of data) identified three groups of firms linked to two discriminatory functionsMultiple comparison tests (MCT) (t-test, Tukey where $\mathrm{n}$ is uneven, Scheffe test, least significant difference [LSD] and Bonferroni) distinguished the involvement of the groups with respect to the three macro variables. To conclude, a multiple regression analysis of ascending stepwise regression (produced by taking into account the three existing enterprise groups) identified the explanatory variables of the dependent macro variable (Development) by reducing the risk of their collinearity.

\section{Results}

\subsection{Three groups and two discriminant functions identified}

The Volume, Velocity and Variety macro variables enabled typological analysis to analyze the various data utilization policies conducted by French automobile dealers. Barycenter scores are shown in brackets $(\mathrm{G})$ below. To reiterate, we used k-means clustering to create the groups of firms.

Composed of 12 small businesses, the No data group is defined by data that are not very voluminous $(G=0.546)$, not very varied $(G=-0.545)$ and whose operating velocity is neither reduced $(\mathrm{G}=-0.545)$ nor high $(\mathrm{G}=-1.643)$.

Composed of 75 medium-sized businesses, the Big data group is defined by data that are very voluminous $(G=0.152)$, very varied $(G=0.336)$ and whose operating velocity is high $(G=$ $0.221)$. 
Composed of 25 small businesses, the Smart data group is defined by data that are small in volume $(G=1.193)$, not very varied $(G=-0.811)$ and whose operating velocity is high $(G=$ $0.127)$.

The above classification has a discriminatory power of $96.88 \%$. According to the Fisher's and Wilks' lambda tests we conducted, the Volume, Velocity and Variety macro variables best discriminate among firms. Two discriminant functions (with $87.20 \%$ discriminating power) were identified as a result of the analysis. The Extended data exploitation function characterizes the Big data group with positive scores for managing a high volume and variety of data. The Intelligent data exploitation function characterizes the Smart data group with positive scores for a high reaction velocity in response to a mainly low data volume.

\subsection{Characteristics of data utilization and automobile dealer development}

What are the distinctive features of the relationship between firms' development and the data utilization for each of the groups? The signs for the barycenters $(\mathrm{G})$ and the significance levels of the Fisher's, Student's, and multiple comparison (p) tests are shown in brackets below.

Analysis of the barycenters reveals that the No data group uses its data to focus specifically on the quality of its offers $(\mathrm{G}>0)$ compared to the other groups. Instead, the Big data group accessses new opportunities through its data utilization $(\mathrm{G}>0)$. The Smart data group distinguishes itself through the development of its sales thanks to data $(G>0)$. Finally, the Fisher's tests underline a significant difference $(\mathrm{p}<0.05)$ among the three groups of dealers regarding the three areas of development analyzed (quality, sales and opportunities).

In the context of the MCTs, the Big data group differs from the No data group in terms of the impact of data on offer quality $(\mathrm{p}<0.005)$, sales $(\mathrm{p}<0.005)$ and access to new business opportunities ( $\mathrm{p}<0.05)$. In addition, the Smart data group is particularly different from the No data group with regard to the role of data in the quality of its offer $(\mathrm{p}<0.005)$. When we combine the Big data and Smart data groups, the Student's t-test indicates that this new set differs from the No data group in terms of the three forms of development analyzed $(\mathrm{p}<0.05)$. To clarify this analysis, we focus on the MCTs of the items related to each of the variables.

For the Quality variable, the items "With data, your company reduces returns" and "With data, your company reduces the defect rate" indicate that the Big data group differs from the No data group ( $\mathrm{p}<0.05)$. As for the item "Thanks to data, your company is improving the quality of its offerings", the Big data ( $<$ 0.001) and Smart data ( $<$ < 0.05) groups differ from the No data 
group. When we group together firms that have a data utilization policy, the Student's t-test indicates that this new set differs from the No data group $(\mathrm{p}>0.01)$ for these three items.

For the Sales variable, the items "Your data allow you to better achieve your sales objectives", "Your data allow you to increase your sales" and "Your data allow you to better face the competition" underline that the Big data group differs from the No data group ( $<<0.05)$. As for the item "Your data allow you to stimulate demand more effectively", the Big data ( $\mathrm{p}<$ $0.001)$ and Smart data ( $<$ 0.005) groups are again different from the No data group. When we group together firms that have a data utilization policy, the Student's t-test indicates that this new set differs from the No data group $(\mathrm{p}>0.01)$ for these four items.

Finally, for the Opportunities variable, only the item "Data help your company to improve its work processes (organization of tasks, deadlines, budgets, etc.)" indicates that the Big data group differs from the No data group $(\mathrm{p}<0.05)$. When we group together firms that have a data utilization policy, the Student's t-test reports that this new set differs from the No data group $(\mathrm{p}>0.01)$ for this item.

In contrast to automobile dealers who do not actively manage their data (No data group), those who deploy a big data or smart data policy favor the development of their business to benefit from the quality of their offer and offer dynamic sales and access to business and management opportunities. Our hypotheses H1, H2 and H3 are, therefore, validated. However, it appears that a 'massive' data utilization policy (big data) is oriented more towards the overall improvement of existing development activities and operating methods, while smart data utilization is more focused on preparing future operations concerning sales and the quality of offers.

\subsection{Determinants of dealers' development according to their data utilization}

For each group of dealers, the stepwise regression model examines alternately the Quality of offers, Sales and new Opportunities as dependent variables (see Table 3). For simplicity, we only produce the significant results for the Big data and Smart data groups in this section. 
Table 3. Stepwise regression analysis

\begin{tabular}{|c|c|c|c|}
\hline \multirow[b]{2}{*}{ Independent variables } & \multicolumn{3}{|c|}{ Dependent variable : Quality } \\
\hline & No data & Big data & Smart data \\
\hline Flexibility & \multirow{4}{*}{$\begin{array}{l}-0.351(*) \\
0.737(*) \\
0.864(*)\end{array}$} & \multirow{4}{*}{$\begin{array}{c}0.249(* * *) \\
0.378(*) \\
0.294(*) \\
\end{array}$} & \multirow{4}{*}{$0.485(*)$} \\
\hline Satisfaction & & & \\
\hline Opportunities & & & \\
\hline Delivery times & & & \\
\hline$R / R^{2} / R^{2} a j$ & $0.989 / 0.977 / 0.969$ & $0.767 / 0.588 / 0.571$ & $0.661 / 0.437 / 0.413$ \\
\hline Fisher tests & $115.413(*)$ & $33.792(*)$ & $17.873(*)$ \\
\hline
\end{tabular}

\begin{tabular}{|c|c|c|c|}
\hline \multirow[b]{2}{*}{ Independent variables } & \multicolumn{3}{|c|}{ Dependent variable : Sales } \\
\hline & No data & Big data & Smart data \\
\hline Satisfaction & \multirow{7}{*}{$\begin{array}{c}0.722(*) \\
0.557(* *) \\
0.266(* * *)\end{array}$} & \multirow[t]{2}{*}{$0.272(* *)$} & \multirow{7}{*}{$\begin{array}{c}0.591(*) \\
0.198(* * *) \\
0.446(* *) \\
-0.207(* *)\end{array}$} \\
\hline High velocity & & & \\
\hline Personal sources & & $0.158(* *)$ & \\
\hline Relational quality & & $0.329(* *)$ & \\
\hline Opportunities & & \multirow[t]{3}{*}{$0.356(*)$} & \\
\hline Flexibility & & & \\
\hline Cost control & & & \\
\hline$R / R^{2} / R^{2} a j$ & $0.963 / 0.927 / 0.899$ & $0.860 / 0.740 / 0.726$ & $0.987 / 0.878 / 0.854$ \\
\hline Fisher tests & $33.766(*)$ & $49.908(*)$ & $36.083(*)$ \\
\hline
\end{tabular}

$(*)=p<0.001 ;(* *)=p<0.01 ;(* * *)=p<0.05$

\begin{tabular}{|c|c|c|c|}
\hline \multirow[b]{2}{*}{ Independent variables } & \multicolumn{3}{|c|}{ Dependent variable : Opportunities } \\
\hline & No data & Big data & Smart data \\
\hline Quality & \multirow[t]{4}{*}{$0.843(*)$} & $0.268(*)$ & \\
\hline Satisfaction & & $0.202(* *)$ & \\
\hline Standard volume & & $-0.137(* *)$ & \\
\hline Sales & & $0.428(*)$ & $0.828(*)$ \\
\hline$R / R^{2} / R^{2} a j$ & $0.888 / 0.788 / 0.766$ & $0.843 / 0.710 / 0.693$ & $0.760 / 0.578 / 0.559$ \\
\hline Fisher tests & $37.099(*)$ & $42.841(*)$ & $31.452(*)$ \\
\hline
\end{tabular}

\subsubsection{Quality related to data}

For the Big data group: increasing customer satisfaction, delivery times and exploiting new opportunities increases the quality of the offers.

For the Smart data group: here too, the increase in customer satisfaction increases the quality of the offers. 


\subsubsection{Sales related to data}

For the Big data group: increased customer satisfaction, customer relationship quality, new opportunities and personal sources are associated with higher sales.

For the Smart data group: increased customer relationship quality, new opportunities, firm flexibility and lower cost control are correlated with higher sales.

\subsubsection{Opportunities related to data}

For the Big data group: an increase in customer satisfaction, the quality of offers and sales and a drop in the standard volume of data are associated with the development of new opportunities exploited by a firm.

For the Smart data group: An increase in sales is linked to the development of new opportunities exploited by a firm.

To conclude, we note that the control variables (Firm size, Sales revenue and Total assets) have no causal links with the Development macro variable.

\section{Discussion}

What are the impacts of data utilization on the development of SMEs in French automobile distribution? Our work answers this question by revealing the existence of various digital policies that influence, each differently, the quality of retailers' offers, the dynamism of their sales and their access to new business opportunities and internal organization. In this sense, our hypotheses $\mathrm{H} 1, \mathrm{H} 2$ and $\mathrm{H} 3$ are validated. However, additional knowledge regarding our initial theoretical model is provided by our empirical study.

The SMEs studied distinguish themselves through the deployment of programs whose volume, velocity and variety of use of data diverge. The analysis of their digital management distinguishes three groups according to the three-dimensional 3Vs model (Laney, 2001): no data dealers, who do not practice any form of management; dealers who practice a form of big data; and those who practice a form of smart data. A big data policy is characterized by the management of a large volume of data, which is also highly varied and has a high operating velocity. Such a firm uses a variety of recent and old data (texts, figures, images, etc.) in real time and on an ongoing basis to guide its decisions, which are always instantaneous and 
continuous. Conversely, a smart data policy is based on a smaller volume and variety of data, which are exploited in both fast and slow time frames. Thus, smart data mobilize specific and contextualized data to a problem, domain, etc., while big data reveal a more global and general approach. A smart data SME is also differentiated by its ability to continually or punctually inform itself and then make either instantaneous or deferred decisions. This management mode, characterized by the mobilization of data that are no longer 'massive' but 'intelligent', is specific. Managers are, therefore, able to mobilize their data quickly, depending on the level of exploitation and decision making required. Moreover, no data group is mainly composed of agents, garages or dealers. It is interesting to note that when we compare the Big data and Smart data groups with the No data group, the proportion of dealers is higher and the proportions of garages and agents are lower. Therefore, dealers seem to be more sensitive to a form of data utilization that is focused on the volume, variety and velocity of data.

Smart data present, therefore, a more complex and dynamic nature than big data. Nevertheless, our results underline that these two types of digital policy have a positive impact on the development of SMEs in automobile distribution. Compared to a lack of data utilization (a no data policy), their deployment significantly improves the quality of their offers, the dynamism of their sales and their access to new business and organizational opportunities. More specifically, the issue of quality is particularly important for dealers, whether or not they have a digital policy. Data utilization is, therefore, logically dedicated to optimizing quality. However, quality appears to be a more central issue for a smart data program, which is focused on improving future offers. In turn, a big data program is oriented more towards optimizing the ongoing operations linked to existing offers (such as reducing returns and defect rates). Optimizing smart data is thus confirmed as a more specific and strategic policy than big data, which, in turn, intervenes more operationally and more broadly in all areas of a firm's development. This is also true in the sales area. Dealers are almost the only category with a vision and a global offer for customers. They extract from big data or smart data current and prospective analyses of markets and customer needs. For dealers, therefore, data utilization is a more important issue than for the other firm categories. Big data support dealers' sales promotion by improving their ongoing commercial development (helping them to reach their objectives, increase sales, etc.). Smart data are, instead, used to stimulate future demand. While 'massive' data are used to support ongoing sales efforts, 'intelligent' data are focused on preparing plans to attract potential customers. Finally, this operational dimension of big data is 
once again emphasized through its influence on the improvement of existing work processes (e.g. the organization of the tasks, deadlines, budgets, etc. of the automobile dealer). For their part, smart data are not particularly focused on the organizational area of an SME.

However, despite their different natures and fields of intervention, big data and smart data policies operate certain common levers to increase the development of SMEs automobile dealers. Thus, customer satisfaction and the quality of the relationship with the dealer appear to be two major determinants targeted by digital policies. For example, regular and privileged exchanges with customers are particularly strengthened and directly influence dealers' sales, regardless of the nature of their data utilization. Nevertheless, it appears that relational quality is particularly mobilized and influential in commercial action during a smart data program. As part of a big data policy, sales growth is stimulated by the identification of new business opportunities and internal organization for the firm. Openness to new sectors and territories or the development of new ways of working within SMEs is favoured more by the exploitation of 'massive' data and less so by the exploitation of 'intelligent' data. The generalist and operational approach of big data certainly helps to generate a better global analysis of existing opportunities related to the intra- and inter-organizational environments of small dealers. For its part, a smart data policy is positioned in a more proactive and strategic role, enabling the SME to act flexibly with respect to performance results (such as modifying the design, production and distribution of offers). The feedback generated by sales improvement is then exploited using intelligent data to offer new development paths to the automobile SME. For example, the stimulation of demand by a smart data program is used for the future expansion of its offers or for opening new markets. Therefore, while big data and smart data have a positive impact on the development of SMEs, they differ in the manner of the impact.

\section{Conclusion}

In a period in which data are becoming increasingly strategic for firms, a large majority of SMEs in the French automobile distribution sector have developed big data or smart data policies to support the development of their business. The quality of their offers, the dynamism of their sales and their access to new business and internal organization opportunities are thus encouraged by the management of 'massive' or 'intelligent' data. However, while the influence of these digital policies on SMEs' development is emphasized by our empirical study, it also tells us about their differentiation in terms of their respective natures, fields of intervention and 
means of action. In this sense, a big data policy develops a 'massive' exploitation of data in order to improve rapidly and globally all the domains related to SME development. It therefore intervenes both in the quality of the offers, the sales volume and the opportunities to be seized by the dealer. It is through the operational and short-term improvement of existing SME operations that big data bring added value. Conversely, a smart data policy is used in a more precise, forward-looking and strategic approach. This mobilizes small and specific samples of data to prepare, within varying timescales, the changes to be made in certain targeted application areas (such as improving the quality of offers and sales dynamism).

The managerial contributions of this research are related to the awareness that the decision makers in small car dealerships require to implement a data policy in their organization to improve the quality of offers, the dynamism of sales and access to new business and internal organization opportunities. Consequently, the technical and organizational difficulties associated with data utilization should no longer be an obstacle to their use. In our study, a minority of small French car dealerships do not use data to develop their business. Overall, the reluctance to use this technology (perceived as being too complex) seems to have been overcome by small organizations and their leaders appear to have realized the need to leverage data to grow their business. The awareness of decision makers is all the more important as their involvement is decisive for the success of such an approach within an SME. However, SME decision makers must also understand that it is necessary to manage data differently depending on whether they want to improve the quality of their offers, the dynamism of their sales or their access to new business and internal organization opportunities. Each data policy has a different impact on the development of a small car dealership. To demonstrate this, our study presents a typology of data policies and their impacts in order to guide the choice of decision makers. Decision makers will then be able to give their organization the capacity to identify, mobilize and configure an adequate volume, variety and velocity of data according to the nature of the developments they desire. Furthermore, they will be able to implement the actions necessary to develop several data policies based on variations in their developmental aims.

In light of the above, our study presents several methodological and empirical limitations that need to be taken into account when reading its results. First, we propose a static approach (rather than one that is process-based) to the phenomenon because our method is quantitative. Second, our questionnaire consists of intuitive items that produced subjective statements from the respondents (although we avoided quantifying items that could result in a large number of non-responses). Finally, our analysis remains comprehensive but future work could focus on 
aspects such as the tension that may emerge between manufacturers and dealers regarding data governance or the influence of the digital policies we have characterized on the development of each of the automobile distribution activities (new and used vehicle sales, parts sales, and after-sales).

\section{References}

Alles, M.G., 2015. Drivers of the use and facilitators and obstacles of the evolution of big data by the audit profession. Accounting Horizons, 29(2) : 439-449.

ANFA - Association Nationale pour la Formation Automobile, 2016. Rapport d'activité 2015 : $1-2$.

Blanchard, R. and O'sullivan, K., 2015. Big data risk and opportunity: having an action plan to address both can add tremendous value to the organization. Internal Auditor, October : 165 .

Boyer, J.M., 2016. La tarification et le big data: quelles opportunités?. Revue d'Economie Financière, 120(4) : 81-92.

Brown-Liburd, H., Issa, H. and Lombardi, D., 2015. Behavioral implications of big data's impact on audit judgment and decision making and future research directions. Accounting Horizons, 29(2) : 451-468.

Brulhart, F. and Moncef, B., 2010. L'impact des pratiques de supply chain management sur la performance de l'entreprise. Finance Contrôle Stratégie, Association FCS, 13(1) : 33-66.

IDC, 2016. Les attitudes des entreprises françaises face au cloud. Etude IDC France:1-25.

CCM Benchmark Institut (2015), « Automobile et digital : l'impact d'internet sur les pratiques d'achat », http://www.ccmbenchmark.com/institut/blog/infographie-automobile-et-digital/

Chandler, D., 2015. A world without causation: big data and the coming of age of posthumanism. Millennium: Journal of International Studies, 43(3): 1-19.

Chen, D. Q., Preston, D. S. and Swink, M., 2015. How the use of big data analytics affects value creation in supply chain management. Journal of Management Information Systems, 32(4): 4-39. 
Cetindamara, D., Phaalb, R. and Probertb, D.R. 2016. Technology management as a profession and the challenges ahead. Journal of Engineering and Technology Management, 41: 1-13.

Davenport, T. H. and Patil, D. J., 2012. Data scientist: the sexiest job of the 21 st century. Harvard Business Review, 10: 70-76.

Laney, D., 2001. 3D data utilization: controlling data volume, velocity and variety. Meta Group Inc., https://blogs.gartner.com/doug-laney/files/2012/01/ad949-3D-DataManagement-Controlling-Data-Volume-Velocity-and-Variety.pdf : 1-3.

George, G., Haas, M. and Pentland, A., 2014. From the editors: big data and management. Academy of Management Journal, 57(2): 321-326.

Goes, P.B., 2014. Big data and IS research. MIS Quarterly, 38(3): 3-8.

Golia, N., 2013. What big data means for infrastructure costs. Insurance and Technology, May: $30-31$.

Grimm, M. and Konig Ingentis, C., 2015. Big data. Big challenge. Big chance. Workforce Solutions Review, 6(6): 24-25.

Huang, P.C. and Huang, P.S., 2015. When big data gets small. International Journal of Organizational Innovation, 8(2):100-117.

Kleinschmidt, E.J., De Brentani, U. and Salomo, S., 2007. Performance of global new product development programs: a resource-based view. Journal of Product Innovation Management, 24(5): 419-441.

Liébana-Cabanillasa, F. and Alonso-Dos-Santos, M. 2016. Factors that determine the adoption of Facebook commerce: The moderating effect of age. Journal of Engineering and Technology Management, 44: 1-18.

Manyika, J., Chui, M., Brown, B., Bughin, J., Dobbs, R., Roxburgh, C. and Byers, A.H., 2011. Big data: the next frontier for innovation, competition, and productivity. McKinsey Global Institute.

Mcafee, A. and Brynjolfsson, E., 2012. Big data: the management revolution. Harvard Business Review, 92(10): 59-68. 
Oxford Economics Survey, 2013. How successful SMEs are reinventing global business. Oxford Economics Editions: 1-14.

Pricewaterhousecoopers, 2016. Connected car report 2016. Opportunities, risk, and turmoil on the road to autonomous vehicles. https://www.pwc.fr/fr/assets/files/pdf/2016/09/connected-car.pdf: 1-64.

Samani, N.D. and Moghaddam, A.Z., 2014. The presentation of model and primary index for identification and measuring the effective factors on customer satisfaction and loyalty in the automobile industry. New Marketing Research Journal, 3(4): 385-399.

Sen, D., Ozturk, M. and Vayvay, O., 2016. An overview of big data for growth in SMEs, 12th International Strategic Management Conference. ISMC 2016, 28-30 October 2016, Antalya, Turkey: 159-167.

Soroka, A. J., Liu, Y., Han, L. and Haleem, M.S., 2017. Big data driven customer insights for SMEs in redistributed manufacturing. The 50th CIRP Conference on Manufacturing Systems: 692-697.

Wagner, M., Bachor, V. and.Ngai E.W.T., 2014. Engineering and technology management for sustainable business development: Introductory remarks on the role of technology and regulation. Journal of Engineering and Technology Management, 34: 1-8.

Warren, D., Moffitt, K. and Byrnes, P., 2015. How accounting records will change with big data. Accounting Horizons, 29(2) :1-25.

Xiang, T., 2013. L’impact des coopérations en termes de ressources et d'activités sur la performance: une étude du réseau logistique en Chine. Logistique et Supply Chain Management [Logistics and Supply Chain Management], 21(3) : 41-56. 


\section{Appendix}

\section{Questionnaire}

\begin{tabular}{|c|c|c|}
\hline $\begin{array}{l}\text { Macro- } \\
\text { variable }\end{array}$ & Variable & Item \\
\hline \multirow{15}{*}{ Development } & \multirow{5}{*}{ Quality } & With data, your business... \\
\hline & & ...maintains the quality of its offers. \\
\hline & & ...improves the quality of its offers. \\
\hline & & ...reduces the defect rate. \\
\hline & & ...reduces the rate of returns. \\
\hline & \multirow{5}{*}{ Sales } & Your data allow you to better... \\
\hline & & ...stimulate demand. \\
\hline & & ...increase your sales. \\
\hline & & ...face the competition. \\
\hline & & ...achieve your sales goals. \\
\hline & \multirow{5}{*}{ Opportunities } & Data help your business to... \\
\hline & & ...develop new ways of working (methods, tools, etc.). \\
\hline & & ...advance its current offerings. \\
\hline & & ...open up to new markets (industry and/or country). \\
\hline & & ...improve the work processes (organization of tasks, deadlines, budgets, etc.). \\
\hline \multirow{10}{*}{ Velocity } & \multirow{5}{*}{ Reduced } & $\begin{array}{l}\text { Your company is informed about the topics that interest it (trends, } \\
\text { players, etc.)... }\end{array}$ \\
\hline & & ...in a discontinuous flow (punctually). \\
\hline & & ...in deferred time (after a certain delay). \\
\hline & & So your data help you make decisions... \\
\hline & & ...in a discontinuous flow (punctually). \\
\hline & \multirow{5}{*}{ High } & $\begin{array}{l}\text { Your company is informed about the topics that interest it (trends, } \\
\text { players, etc.)... }\end{array}$ \\
\hline & & ...in real time (instantly). \\
\hline & & So your data help you make decisions... \\
\hline & & ...in a continuous flow (permanently). \\
\hline & & ...in real time (instantly). \\
\hline \multirow{4}{*}{\multicolumn{2}{|c|}{ Variety }} & Your company uses... \\
\hline & & ...several types of data (encrypted data, texts, images, videos, etc.). \\
\hline & & ...old data (more than a year). \\
\hline & & ...recent data (less than a year). \\
\hline \multirow{5}{*}{ Volume } & \multirow{4}{*}{ Low } & According to you, your company COLLECTS... \\
\hline & & $\begin{array}{l}\text {... a "low" volume of data per year (one or more CD Roms, USB storage keys, } \\
\text { etc.). }\end{array}$ \\
\hline & & According to you, your company PRODUCES... \\
\hline & & $\begin{array}{l}\text {... a "low" volume of data per year (one or more CD Roms, USB storage keys, } \\
\text { etc.). }\end{array}$ \\
\hline & Standard & According to you, your company COLLECTS... \\
\hline
\end{tabular}




\begin{tabular}{|c|c|c|}
\hline & & ... a "standard" volume of data per year (one or more storage hard drives). \\
\hline & & According to you, your company PRODUCES... \\
\hline & & ... a "standard" volume of data per year (one or more storage hard drives). \\
\hline & \multirow{4}{*}{ High } & According to you, your company COLLECTS... \\
\hline & & ...a "large" volume of data per year (one or more storage servers). \\
\hline & & According to you, your company PRODUCES... \\
\hline & & ... a "large" volume of data per year (one or more storage servers). \\
\hline \multirow{5}{*}{$\begin{array}{c}\text { Firm } \\
\text { sources }\end{array}$} & \multirow{3}{*}{ Institutional } & Generally, you collect data from... \\
\hline & & ...professional organizations (federations, clubs, etc.). \\
\hline & & ...public bodies (ministries, INSEE, communities, etc.). \\
\hline & \multirow{2}{*}{ Horizontal } & ...from your competitors. \\
\hline & & ...your allies (partnerships with competitors). \\
\hline \multirow{7}{*}{$\begin{array}{l}\text { Collaborator } \\
\text { sources }\end{array}$} & \multirow{4}{*}{ Personal } & Personally, you collect information through your relationships... \\
\hline & & ...with former classmates. \\
\hline & & ...with friends. \\
\hline & & ...with family. \\
\hline & \multirow{3}{*}{ Professional } & Personally, you collect information through your relationships... \\
\hline & & ...with members of your association. \\
\hline & & ...with members of your union. \\
\hline \multirow{21}{*}{$\begin{array}{c}\text { Customer } \\
\text { relationship }\end{array}$} & \multirow{5}{*}{$\begin{array}{l}\text { Relational } \\
\text { quality }\end{array}$} & Your data allow you... \\
\hline & & ...to provide a faster response to your customers. \\
\hline & & ...to interact regularly with your customers. \\
\hline & & ...to have a relationship of trust with your customers. \\
\hline & & ...to build a long-term relationship with your customers. \\
\hline & \multirow{5}{*}{$\begin{array}{l}\text { Delivery } \\
\text { times }\end{array}$} & Your data allow you to better... \\
\hline & & ...deliver at short notice. \\
\hline & & ...meet delivery times to customers. \\
\hline & & ...fulfil certain urgent or exceptional shipments. \\
\hline & & ...deliver your products intact. \\
\hline & \multirow{5}{*}{ Follow-up } & Your data allow you... \\
\hline & & ...to work on your customers' complaints. \\
\hline & & ...to seek to better involve your customers in your activities. \\
\hline & & ...to facilitate customer access to your customer support. \\
\hline & & ...to deal with unexpected requests or events. \\
\hline & \multirow{6}{*}{$\begin{array}{c}\text { Customer } \\
\text { satisfaction }\end{array}$} & Your data allow you... \\
\hline & & ...to reduce complaints from your customers. \\
\hline & & ...to nurture the trust of your customers. \\
\hline & & ...to ensure a high rate of "customer satisfaction". \\
\hline & & ...to measure customer satisfaction. \\
\hline & & ...to increase customer satisfaction. \\
\hline \multirow{4}{*}{ Exploitation } & \multirow{4}{*}{ Flexibility } & With data, your business is able to be quicker at changing... \\
\hline & & ...its production volumes (up or down). \\
\hline & & ...its means of production (materials, supplies, organization of work, etc.). \\
\hline & & ...the conception of its offers (characteristics, design, etc.). \\
\hline
\end{tabular}


...its marketing decisions (What do I sell? How much do I sell? Where do I sell it?).

...the distribution of its offers (deadline, volume, etc.).

With data, your business...

...keeps costs down.

Cost control ...improves the costing of budgets.

...improves the management of costs linked to its activity. ...reduces costs.

Data help your business improve...

Human ...the involvement of its collaborators.

resources

...the satisfaction of its employees.

...the exchange of knowledge among its employees.

...the participation of its employees in meetings, events, projects, etc. ...the motivation of its employees. 